\title{
Applications of a DAD-HPLC method for determination of loratadine on biological samples
}

\author{
Georgeta PAVALACHE ${ }^{* a}$, Nicoleta MATEI ${ }^{\mathrm{b}}$, Antoanela POPESCU ${ }^{\mathrm{a}}$ and Verginica SCHRODER ${ }^{\mathrm{a}}$ \\ ${ }^{a}$ Faculty of Pharmacy, "Ovidius" University of Constanta, Romania \\ ${ }^{b}$ Faculty of Applied Sciences and Engineering, "Ovidius” University of Constanta, Romania
}

\begin{abstract}
The aim of research is to assess the active substance by a HPLC method for the separation and quantitative determination of loratadine. The method has been developed and validated on the standard solutions, in previous research. The current study was undertaken to present the results obtained from loratadine determination in biological samples (human serum, urine and breast milk). These results may be applicable on patients with different physiological conditions (aging, pregnancy or recently giving birth, etc.) and pathological conditions which may interfere with the metabolism of loratadine. The used HPLC method detected loratadine concentrations in human serum samples, respectively urine samples, at 2 hours after drug administration. The method detected traces of loratadine which passed into breast milk, as well. Data were statistically interpreted using MED CALC 10.2 software. These results show that the applied method can be used for quantitative analysis of loratadine in biological fluids (all permissible limits of quality specifications being in the range 95$105 \%)$.
\end{abstract}

Keywords: loratadine, HPLC, biological samples.

\section{Introduction}

Loratadine is a tricyclic piperidine derivative, orally effective, long-acting, non-sedating, secondgeneration antihistamine with no significant antimuscarinic activity. It is used for the symptomatic relief of allergic conditions, including rhinitis and chronic erythema $[1,2]$. According to the Biopharmaceutics Classification System and based on its poor water solubility and high permeability, loratadine is classified as a class II drug [1]. As a member of this class of drugs, the rate of oral absorption of loratadine is controlled by its dissolution rate in the gastrointestinal tract and, as a result, no more than $80 \%$ of the total dose administered is absorbed. A large part of absorbed substance binds to plasma proteins. Unchanged loratadine is eliminated in the urine and can diffuse into breast milk [1].

They are induced phenomena, at the molecular level, which explains antiallergic activities, such as the inhibition of the release of mediators from mast cells that reduces the inward calcium current activated by the depletion of the intracellular store of calcium. [3]. Also, involve down-regulation of the
H1-receptor-activated nuclear factor- $\kappa \mathrm{B}$, a ubiquitous transcription factor, that binds to the promoter and enhancer regions of many genes that regulate the production of pro inflammatory cytokines and adhesion proteins [3].

In our previous research, it was developed a method of loratadine determination by high performance liquid chromatography, isocratic conditions by detecting it in the ultraviolet at 280 $\mathrm{nm}$. The analysis method was optimized and validated on field $0.5-9.0 \mu \mathrm{g} / \mathrm{mL}$ [4].

The purpose of this paper is to check the performance of the method, as a preamble for further research. Thus, loratadine was dosed in different biological samples: human serum, urine, breast milk, fluids that may contain physiologically, traces of unmetabolized loratadine.

\section{Experimental}

2.1. Chemicals and devices

Loratadine was used (CRS European Pharmacopoeia) for the preparation of standard solutions. 
All other substances are high purity reagents (Merck): methanol for liquid chromatography, phosphoric acid, acetonitrile.

Method runs under the following chromatographic conditions: HPLC Agilent 1200 quaternary pump, DAD, thermostat, degassing system, autosampler; $\mathrm{C} 8$ type column chromatography (Zorbax Eclipse XDB-C8, double heads connected; $150 \mathrm{~mm}$ x $4.6 \mathrm{~mm}$; particle size $5 \mu \mathrm{m} ; \mathrm{t}_{\text {limit }}=60^{\circ} \mathrm{C} ; \mathrm{pH} 2-9$ ); debit: $1.5 \mathrm{~mL} / \mathrm{min}$; Column temperature: $27^{\circ} \mathrm{C}$; injection volume: $10 \mu \mathrm{L}$; mobile phase: acetonitrile / $(10 \mathrm{~g} / \mathrm{L}$ aqueous solution of $\mathrm{NH}_{4} \mathrm{H}_{2} \mathrm{PO}_{4}$ in which $\mathrm{H}_{3} \mathrm{PO}_{4}$ was added $5 \mathrm{~mL}$ ) $11 / 15$ (v/v); detection: UV $\lambda=280 \mathrm{~nm}$ [4].

\subsection{Samples collecting and preparation}

In order to compare the performance of this method with another HPLC method, developed, validated and applied in our previous research, sampling and processing of biological samples was performed identically for both methods [4], [5]: Samples of blood and urine were collected at the same time, from the same 6 healthy volunteers, who have received loratadine orally at a dose of $10 \mathrm{mg}$ once a day (recommended therapeutic dose prospectus), at the same hour (9:00 AM). Volunteers are adult males who had never allergy to the product reviewed. Collecting samples was performed at different time intervals successively: immediately after administration and at 1, 2, 5, 12 and 24 hours.

After sampling, blood samples were centrifuged at $3000 \mathrm{rev} / \mathrm{min}$ for 10 minutes. $1.0 \mathrm{~mL}$ serum was treated with $1.0 \mathrm{~mL}$ of isoamyl alcohol in order to precipitate the serum proteins. After 20 minutes of standing, the mixture was centrifuged at $4000 \mathrm{rev} /$ min for 10 minutes. The supernatant, resulted from the centrifuge process, was analyzed.

After collection, urine samples were treated with isoamyl alcohol $1 / 1(\mathrm{v} / \mathrm{v})$, in order to precipitate the proteins. After 10 minutes of mixing and 20 minutes of resting, the mixture was centrifuged at $4000 \mathrm{rev} /$ min for 10 minutes. It was taken in the supernatant. The method was applied also on breast milk samples taken from a female person diagnosed with cutaneous rash, 2 months after giving birth. Milk samples were taken at various time intervals after administration of antihistamine treatment $(10 \mathrm{mg}$ loratadine). $4 \mathrm{~mL}$ breast milk was mixed with $1 \mathrm{~mL}$ of $10 \%$ trichloroacetic acid, rested for 20 minutes, and then centrifuged at $5500 \mathrm{rev} / \mathrm{min}$ for 15 minutes. A sample of $6 \mu \mathrm{L}$ supernatant was mixed with $1 \mu \mathrm{L} 1 \%$ solution cyanidaldehyde in methanol and rested again for 5 minutes.

\subsection{Methods}

It balances the chromatography column with the mobile phase for 60 minutes. Inject $10 \mu \mathrm{L}$ sample and record the chromatogram with UV detection at $\lambda$ $=280 \mathrm{~nm}$ [5]. Data were statistically interpreted using MED CALC 10.2 software.

\section{Results and Discussions}

The pharmacokinetics of loratadine manifests large inter-individual variability. Loratadine is known to be a substrate for both CYP3A4 and CYP2D6 [6].

The remarkable inter-individual variability of loratadine may be mainly due to its first-pass metabolism. The area under the plasma concentration-time and the maximum concentration for both loratadine and descarboethoxyloratadine in Chinese were higher than those reported in Caucasian. The mean maximum concentration values of loratadine and descarboethoxyloratadine were $16.6 \mu \mathrm{g} / \mathrm{L}$ and $15.6 \mu \mathrm{g} / \mathrm{L}$. These results indicated that loratadine might be faster eliminated in Chinese than in Caucasian. According to these pharmacokinetic results, it would be recommended for loratadine to be taken twice daily at a lower dose in Chinese [7].

It was reported that half-life of loratadine was about $11 \mathrm{~h}$ and that of the active metabolite descarboethoxyloratadine was about $18 \mathrm{~h}$ in Caucasian [8].

\subsection{Determination of loratadine in human serum}

Blood samples were taken at 1 hour, 2 hours, 5 hours, 12 hours and 24 hours after administration. The corresponding chromatograms for the samples were recorded, and the loratadine peak areas were calculated. Figure 1 shows the chromatogram registered for one of the human serum samples taken at 12 hours after administration, at which observed the highest blood concentrations of loratadine. This result is confirmed by another method studied in our previous research, which runs in different chromatographic conditions, to another wavelength and another retention time [5].

The present method proved to be sensitive and easily applied in the dosage of loratadine in human 
serum. By analyzing samples from volunteers, it was observed a slight increase in the concentration of unchanged loratadine in the first period (1-12 hours after administration) and then a fall, due to its metabolism and renal elimination. These values are influenced by both the patient's enzyme system [9] and transport protein [10], since the substance is bound in proportion of $90-97 \%$ to these [11].

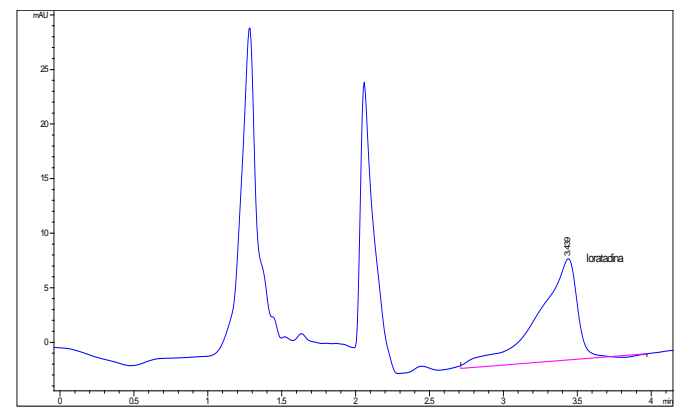

Figure 1. Chromatogram of a sample solution (human serum) at 12 hours after taking antihistamine treatment administration of the drug.

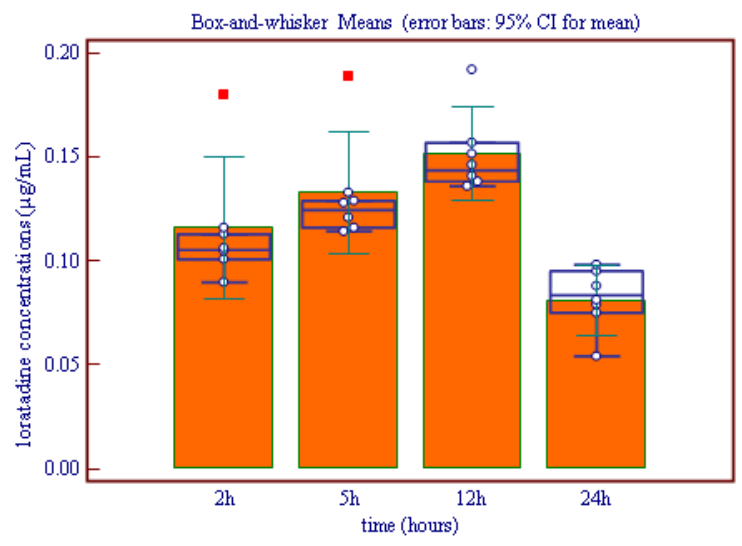

Figure 2. Loratadine concentrations $(\mu \mathrm{g} / \mathrm{mL})$ in blood samples from adult volunteers (6n) at 2, 5, 12, 24 hours

As confirmed by the literature, loratadine is well absorbed orally and has peak plasma in about 2 hours after ingestion. It is metabolized largely to its active metabolite, descarboethoxyloratadine. Unmetabolised loratadine concentration in blood was detected by HPLC method, and its modifying values depending on time were highlighted graphically (Fig. 2).

\subsection{Determination of loratadine in urine}

Urine samples were collected at 1 hour, 2 hours, 12 hours and 24 hours after administration. These samples were processed and analyzed by chromatographic method established. The method proved to be valid and easily applied for dosage the trace of unmetabolised loratadine eliminated in the urine. There were registered chromatograms of the samples and loratadine peak areas were calculated. From the appearance of chromatograms it is observed that peaks of other components of the sample does not interfere with loratadine peak, which makes the method sensitive and specific for this active substance. In figure 3 is presented the chromatogram of a urine sample taken at 12 hours after administration.

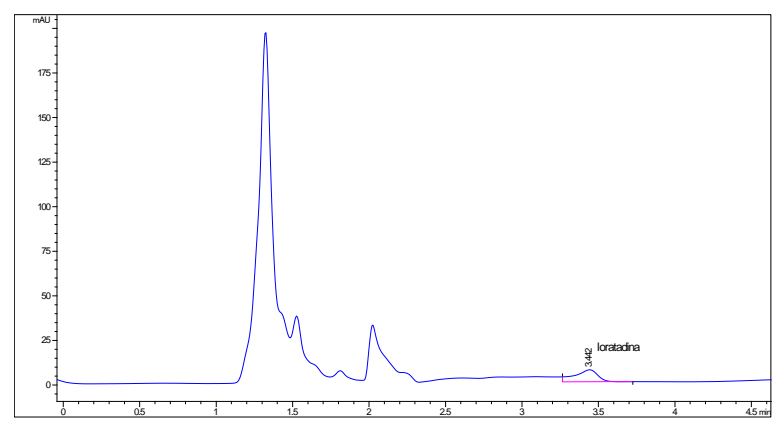

Figure 3. Chromatogram of a urine sample solution at 12 hours after taking antihistamine treatment

Changing the values of loratadine trace concentrations in urine shown in figure 4 indicates significant differences related to blood samples.

As in the case of blood samples, maximum concentration in urine samples was recorded after 12 hours following administration of loratadine. The blood concentrations of loratadine were compared with those in urine and found that the substance increases in both kinds of sample up to approximately 12 hours after administration and then begins to decline as it is being eliminated (Fig. 5). 


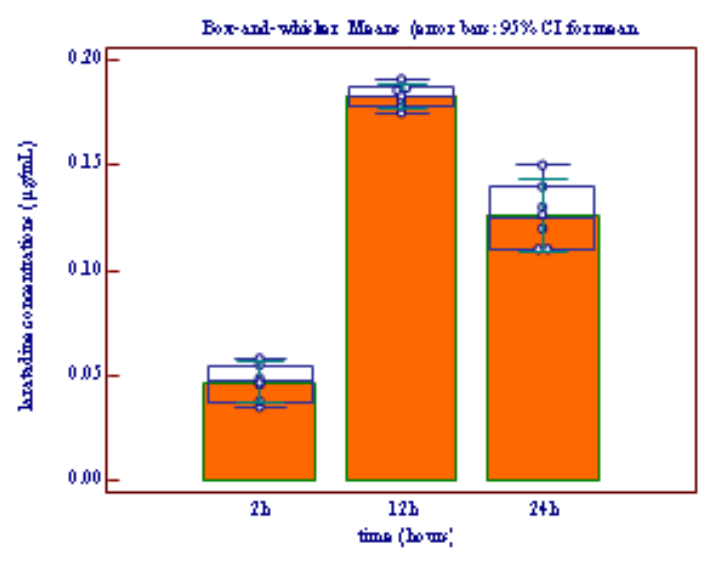

Figure 4. Loratadine concentrations $(\mu \mathrm{g} / \mathrm{mL})$ in urine samples from adult volunteers $(6 n)$ at 2,12 and 24 hours

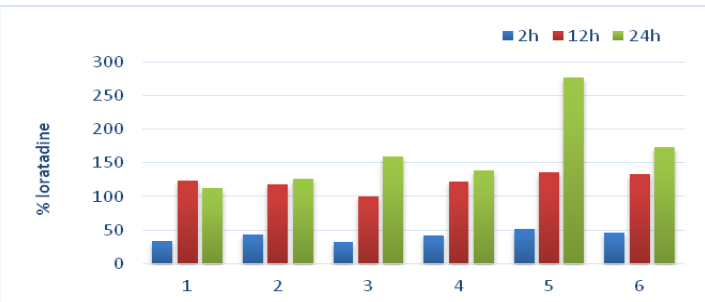

Figure 5. Loratadine level from urine samples at 2 , 12, 24 hours after start doses, showed as percentage (\%) from plasma concentrations in the same period of time.

\subsection{Determination of loratadine in breast milk}

Loratadine in breast milk whereas its peak does not interfere with peaks of other components in the sample. Loratadine is usually compatible with breastfeeding (classified category L-2 by the American Academy of Pediatrics [13]. In the U.S., it is classified as category B in pregnancy, meaning that animal reproduction studies have failed to demonstrate a risk to the fetus, and there are no adequate and well-controlled studies in pregnant women [12].

Loratadine is excreted in breast milk after about 1.5 - 2 hours after dosing [2]. The chromatogram sample taken 3 hours after drug administration is shown in Fig. 6.

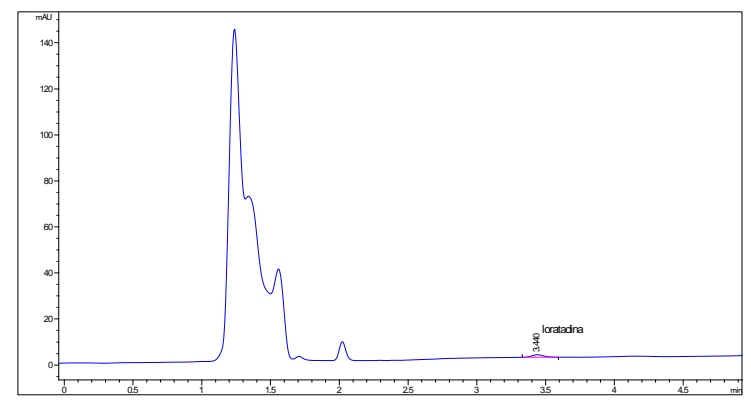

Figure 6. The chromatogram of the sample solution (breast milk) to 3 hours after antihistaminic treatment

The level of concentration in breast milk is very low compared with levels in blood plasma, respectively $3.01-4.33 \%$. Trends milk level can be correlated with those in plasma (figure 7).

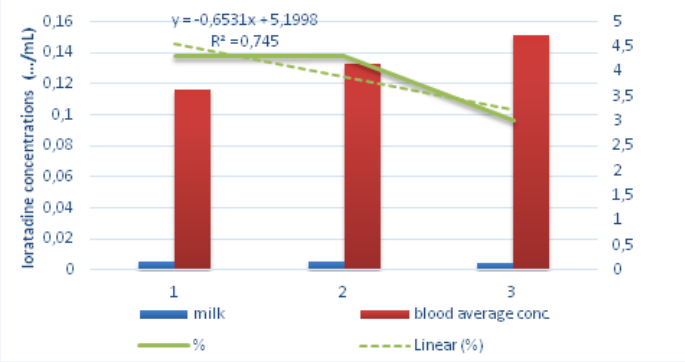

Figure 7. Loratadine concentrations $(\mu \mathrm{g} / \mathrm{mL})$ in milk and plasma samples at 2, 6 and 12 hours after dose administration and linear trend line for percentage differences.

These data are different from other studies: Breast milk concentration-time curves of both loratadine and descarboethoxyloratadine paralleled the plasma concentration-time curves. For loratadine, the plasma maximum concentration was $30.5 \mathrm{ng} / \mathrm{mL}$ at one hour after dosing and the milk maximum concentration was $29.2 \mathrm{ng} / \mathrm{mL}$ in the 0 to 2 hour collection interval. Through 48 hours, the loratadine milk-plasma area under the curve ratio was 1.2 and $4.2 \mu \mathrm{g}$ of loratadine was excreted in breast milk, which was $0.010 \%$ of the administered dose [8].

Loratadine concentration in breast milk increases with time from administration to about 6 hours, then begin to decline. The HPLC method is sensitive and can detect traces of loratadine in breast milk whereas 
its peak does not interfere with peaks of other components in the sample.

\section{Conclusions}

Since the method is intended to be useful in the analysis and control of drug trials, bioequivalence studies and pharmacokinetic, in the present paper were performed applications of the method in biological samples (human serum, urine, breast milk).

Loratadine concentrations found in human serum samples and urine samples are detectable within 2 hours after drug administration. Traces of loratadine that pass into breast milk can be detected by the HPLC method presented.

Retention time peak of loratadine is about 3.8 minutes, which allows the analysis of a large number of samples in a reasonable time.

Application of this method results were compared with results obtained in the same kind of samples using another HPLC method with different working conditions [5]. The method used in present research proved to be simple, selective, accurate, precise and reproducible dosing of loratadine.

Correlating the results of biological samples with metabolic activity of patients, the technique can be applied to indicate different metabolism in order to implement personalized therapeutics.

\section{References}

*e-mail address: georgiana_pavalache @ yahoo.com

[1]. M.Z. Khan, D. Rausl, R. Zanoski, S. Zidar, J.H. Mikulcic and L. Krizmanic, Biol Pharm Bull. 27, 1630-1635 (2004)

[2]. A.N. Cristea, Tratat de farmacologie, Editura Medicală, Bucureşti, pp. 639-659 (2005)
[3]. H. Manal, E.L. Kafrawy and Amina M. Tolba, Journal of American Science, 10, 81-89 (2014)

[4]. G. Pavalache, V. Dorneanu and A. Popescu, Revista de chimie, 67 (1), in press, (2016)

[5]. G. Pavalache, N. Matei, A. Popescu, 14th SGEM GeoConference on Nano, Bio And Green - Technologies For A Sustainable Future, Conference Proceedings 1, 269-276, (2014)

[6]. O. Q. P. Yin, X. J. Shi, B. Tomlinson, M. S. S. Chow, Drug Metabolism and Disposition, , 33 (9), 1283-1287, (2005)

[7]. Y.F. Zhang, X.Y. Chen, D.F. Zhong, Y.M. Dong, Acta Pharmacol Sin, 24, 715-718 (2003)

[8]. J. Hilbert, E. Radwanski, R. Weglein, V. Luc, G. Perentesis and S. Symchowicz, J. Clin Pharmacol, 27, 694-698 (1987)

[9]. A. Ghosal, S. Gupta, R. Ramanathan,Y. Yuan, X. Lu, A.D. Su, N. Alvarez, S. Zbaida, S.K. Chowdhury and K.B. Alton, Drug Metab Lett. 3, 162-170 (2009)

[10]. W. Er-Jia, N.C. Christopher, P.C. Robert and W.J. William, 29, 1080-1083 (2001)

[11]. J.G. Hardman, L.E. Limbird, P.B. Molinoff, R.W. Ruddon, A.G. Goodman (Eds.). Goodman and Gilman's the Pharmacological Basis of Therapeutics. $9^{\text {th }}$ Ed. New York, NY: McGraw-Hill, p. 588 (1996)

[12]. N.F. Adkinson Jr, J.W. Yunginger, W.W. Busse, B.S. Bochner, S.T. Holgate, F.E.R. Simons, Middleton's allergy: principles \& practice. Philadelphia: Mosby, 834-869, (2003)

[13]. W. Jasek, Austria-Codex, Vienna: Österreichischer Apothekerverlag, ISBN 9783-85200-181-4, pp. 1731-1734 (2007)

Received: 29 April 2015

Received in revised form: 8 June 2015 Accepted: 9 June 2015 